\section{Reflexionen über den Ministerialerlass rom 26. März d. J., betreffend die Verwerthung des Fleisches perlsüchtigen Rindviehs. ${ }^{1}$ )}

Von Dr. phil. u. med. H. C. Plant, Leipzig.

Der preussische Ministerialerlass vom 26. März d. J., welcher Stellung zu der wichtigen Frage nimmt, inwieweit das Fleisch perlsüchtigen Rindviehs für die menschliche Nahrung verwerthbar ist, dürfte nicht geeignet sein, vortheilhaft auf unsere bygienischen Verhältnisse zu wirken. Selbst für den Fall es sich bestătigen sollte, dass das nunmehr zum freien Verkauf zugelassene Fleisch absolut unschädlich für den Menschen ist - eine Frage, die nach den Verhandlungen des VII. Internationalen Congresses in London $(10,-17$. Aug. 1891) doch mindestens noch als unentschieden hingestellt werden muss -, so würde dennoch dieser Erlass dazu beitragen
müssen, die schon an und für sich enorme Verbreitung der Tuberculose unter den Rindvieh noch mehr zu fördern. Der Erlass nämlich schneidet den einzig richtigen Weg, den man bei der Bekämpfung dieser Seuche einschlagen kann, rundweg ab, indem er verhindert, dass durch eine streng durchgeführte Fleischbeschau, mit all' ihren verlustsetzenden Consequenzen, der Viehhalter und Züchter gezwungen wird, selbst gegen diese Seuche Front $\mathrm{zu}$ machen, da in der That der Landwirth allein in der Lage ist, durch Vorsicht ${ }^{2}$ ) beim Ankauf von Vieh, durch Ausschaltung aller verdächtigen Thiere und Anwendung der diagnostischen Tuberkulinimpfung, die Ausbreitung der Tuberculose wirksam zu bekämpfen. Dieser Ansicht sind auch viele Landwirthe, das beweisen die zahlreichen Einführungen der Tuberkulinimpfung auf den Gütern, die doch noch mit sehr hohen Kosten verbunden ist. Freilich werden derartige Versuche, welche unter dem Drucke der strengen Fleischbeschan gemacht wurden, nunmehr ihr Ende erreichen, denn welcher Landwirth möchte wohl durch kostspielige hygienische Maassnahmen die Rentabilität seiner Viehhaltung herabdrücken, wenn er weiss, dass tuberculöses Vieh sich beinahe ebenso leicht verwerthen lässt wie gesundes? Im Gegentheil wird in Zukunft mancher rationelle Landwirth daran denken, sich wieder mehr auf die Mastviehwirthschaft zu legen, in der Hoffnung, dass der neue Erlass eine. Hebung dieses. Geschäftszweiges mit sich bringen werde. Wie sehr aber ausgedehnte Mastviehwirthschaften durch den schnellen Wechsel im Viehbestando die Gefahren der Ausbreitung der Tuberculose vermehren, bedarf wohl nicht erst einer besonderen Auseinandersetzung.

Wenn man nun glauben sollte, eine Verbreitung der Tuberculose unter den Rindern wăre für den Menschen irrelevant, da ja das Muskelfleisch der Schlachtthiere nicht infectiös sei, so wäre das ein gewaltiger Irrthum, denn die Ausbreitung der Tuberculose unter den Rindern wird mit absoluter Sicherheit auch die unter den Menschen steigern. Denn es steht unumstösslich fest, dass die Milch tuberculöser Rinder, selbst wenn das Euter nicht erkrankt ist, besonders für jugendliche Individuen infectiös ist, auch dann, wenn sie vor dem Genuss aufgekocht wird. Weiter wissen wir mit Bestimmtheit, dass Milchwirthschaften von Mastviehwirthschaften, besonders in grossen Städten, aus rein wirthschaftlichen Gründen nicht räumlich getrennt werden können, und eine Zunahme der Krankheit unter den Mastthieren auch eine solche unter dem Milchvieh zur Folge haben muss, besonders weil die auf Milchproduction hochgezüchteten Thiere eine ausserordentliche Disposition zur Tuberculose zeigen. Wir werden also mit ansehen müssen, wie die niedere Bevölkerung, die einmal nicht glauben will und wird, dass Kindermilch vor dem Genusse ordentlich sterilisirt sein muss, ihre Kinder in noch höherem Grade, als dies jetzt schon der Fall ist, scrophulös oder tuberçulös aufzieht.

Das ist der Schaden des Erlasses, wenn dem Fleisch tuberculöser Thiere eine Infectionsfähigkeit nicht innewohnt.

Weun aber nun, wie nicht selten bei derartigen Fragen beobachtet, es sich nachträglich herausstellen sollte, dass die bis jetzt angestellten Experimente wohl für die untersuchten Thierarten beweiskräftig, nicht aber für den Menschen gelten, was dann? Oder wenn es sich zeigte, dass neben den Bacillen auch ihre Stoffwechselproducte in Frage kämen und, unter dem Genusse des sie enthaltenden Fleisches, leichte Tuberculosen sich sichtlich verschlimmerten? Dann wäre allerdings die Frage von der Schädlichkeit des fuberculösen Fleisches aufs sicherste beantwortet, freilich durch ein inhumanes Massenexperiment, wie es unserer Wissenschaft wenig Ehre machen würde Nach meiner Ansicht, und ich glaube als früherer Landwirth, als ehemaliger Laboratoriumsassistent hiesiger Universitätsveterinárklinik und jetziger Arzt das Recht und die Pflicht zu haben, dieselbe zu äussern, bedeutet der Erlass ein unnöthiges Aufgeben des Kampfes gegen die Tuberculose, und zwar in einem Augenblicke, in dem die Bekämpfung derselben durch die systematisch angewandte Impfung mit Tuberkulin mehr Aussicht auf Erfolg bat, als in irgend einer. Zeitperiode vorher.

1) Eingesandt am 18. April 1892.

2) Zuziehung eines Thierarztes. 